\title{
Seroprevalencia de Brucelosis Canina en el Distrito de Los Olivos, Lima, Perú
}

\author{
Seroprevalence of Canine Brucellosis in the District of Los Olivos, Lima, \\ Peru
}

\author{
María Maza V. ${ }^{1}$, Siever Morales C. ${ }^{1,2}$
}

\section{Resumen}

El estudio evaluó la seroprevalencia de brucelosis canina en el distrito de Los Olivos, Lima, Perú, mediante el método diagnóstico de Inmunodifusión en Gel de Agar (IDGA). Se recolectaron 288 muestras de sangre de canes mayores de dos meses de edad. Los sueros resultantes se analizaron para la determinación de seropositividad a Brucella canis. La seroprevalencia de brucelosis canina fue de $4.9 \pm 1.8 \%$ (IC 95\%) y una seroprevalencia corregida de $5.3 \pm 2.6 \%$ (IC 95\%), sin encontrar un efecto significativo para las variables edad, sexo, condición fisiológica, hábitos de paseo e historia reproductiva.

Palabras clave: Brucella canis, IDGA, brucelosis

\section{Abstract}

The study evaluated the seroprevalence of canine brucelosis in the district of Los Olivos, Lima, Peru by the Agar Gel Immunodifussion test (AGID). Blood samples $(\mathrm{n}=288)$ were collected from dogs older than 2 months of age. The sera were tested for Brucella canis. The seroprevalence of canine brucelosis was $4.9 \pm 1.8 \%(95 \% \mathrm{CI})$ and the corrected seroprevalence was $5.3 \pm 2.6 \%(95 \% \mathrm{CI})$, without significant association for age, sex, physical condition, indoor/outdoor habits and reproductive history.

Key words: Brucella canis, AGID, brucellosis

\footnotetext{
${ }^{1}$ Laboratorio de Microbiología y Parasitología Veterinaria, Facultad de Medicina Veterinaria, Universidad Nacional Mayor de San Marcos, Lima, Perú

${ }^{2}$ E-mail: sieverm@hotmail.com
}

Recibido: 25 de agosto de 2015

Aceptado para publicación: 15 de diciembre de 2015 


\section{INTRODUCCIÓN}

La brucelosis canina es una enfermedad infecciosa, de curso crónico y carácter zoonótico, ocasionada por la bacteria Brucella canis (Acha y Szyfres, 2003). Es una bacteria Gram negativa, que fue reconocida en 1966 como causante de abortos y pérdidas reproductivas en criaderos de perros de los Estados Unidos (Carmichael y Kenney, 1968). Posteriormente ha sido reportada en varios países, principalmente en América Central y del Sur y en la zona sur de los Estados Unidos, y de forma esporádica en criaderos de perros en Europa y algunos países asiáticos (Castillo et al., 2002).

Los únicos hospedadores naturales de la enfermedad son los cánidos, donde la transmisión ocurre a través de la ingestión de tejidos placentarios contaminados, fetos abortados, descargas vaginales de hembras y semen de machos infectados (Shin y Carmichael, 1999). No obstante, el hombre también puede infectarse accidentalmente, por lo que esta enfermedad tiene carácter zoonótico (Steele et al., 1979; Acha y Szyfres, 2003).

La sintomatología clínica observada en cánidos infectados por $B$. canis puede variar de animales asintomáticos a animales con cuadros de linfadenopatía, así como orquitis, epididimitis y atrofia testicular en machos y pérdidas embrionarias y abortos en hembras (Hollet, 2006). Por otro lado, la brucelosis en humanos puede cursar con cuadros de fiebres recurrentes, hepatitis granulomatosa, esplenomegalia y adenopatía submandibular (Rousseau, 1985; Schoenemann et al., 1986).

En general, las terapias médicas para el tratamiento de la brucelosis canina son imprácticas, debido a su efectividad parcial y tratamiento prolongado, que eleva el costo de la terapia, de allí que las herramientas de prevención y control son de vital importancia. Por otro lado, la eutanasia de animales portadores en criaderos, la castración, el monitoreo y la implementación de programas de cuarentena en animales que ingresan a un criadero han demostrado ser medidas eficaces para el control de la brucelosis canina (Rhoades y Mesfin, 1980; Hollet, 2006). Asimismo, las vacunas contra la brucelosis canina solo confieren una protección moderada y los anticuerpos producidos pueden dificultar la interpretación del diagnóstico serológico (Shin y Carmichael, 1999).

En el Perú, Reyes (1977) reportó 28\% de seropositividad a $B$. canis en perros de Lima Metropolitana, mientras que un estudio posterior realizado por Ramírez et al. (2006) en la Provincia Constitucional del Callao se encontró $15.6 \%$ de seroprevalencia. No se dispone de otros estudios que indiquen la situación actual de la brucelosis canina en el país, de allí que el objetivo del presente trabajo fue determinar la seroprevalencia de brucelosis canina mediante la prueba de inmunodifusión en gel de agar (IDGA) en caninos del distrito de Los Olivos, Lima, así como posibles factores asociados a la enfermedad.

\section{Materiales y Métodos}

\section{Lugar del Estudio}

El estudio se realizó en el distrito de Los Olivos, Lima, Perú, durante los meses de julio a diciembre de 2012. Se contó con la participación conjunta del municipio distrital y las clínicas veterinarias del distrito.

\section{Animales y Tamaño de Muestra}

El número mínimo de caninos requeridos para el estudio fue obtenido mediante la fórmula de estimación de una proporción (Ahlbom y Norell, 1990). Para ello, se consideró una prevalencia referencial de $15 \%$ de acuerdo al estudio de brucelosis canina en el Callao (Ramírez et al., 2006), un valor tabular de $z$ para un nivel de confianza del $95 \%$ y un error máximo permisible de $5 \%$, 
obteniéndose un número mínimo de 196 caninos. Para efectos del estudio, se muestrearon 288 caninos mayores de dos meses de edad y clínicamente sanos.

\section{Toma de Muestras y Procesamiento}

La toma de muestras de sangre se realizó durante la consulta general en centros veterinarios del distrito, así como en las campañas de salud y empadronamiento de canes organizados por la Municipalidad. Los propietarios dieron por escrito su consentimiento informado para la recolección de muestras y su empleo en el estudio. Asimismo, se realizó una encuesta a los propietarios de las mascotas para obtener información sobre la edad ( $<1,1$ a 4,5 a 8 y 9 a 15 años), sexo, condición fisiológica (entero, castrado), hábitos de paseo (sí, no) e historial reproductivo de sus animales (apareado: sí, no). El historial reproductivo en hembras mayores de 12 meses incluyó posibles abortos y nacimientos de crías muertas.

Las muestras de sangre $(3 \mathrm{ml})$ se recolectaron mediante punción en la vena cefálica en tubos al vacío sin anticoagulante (Vacutainer®). Las muestras fueron rotuladas y trasladadas en refrigeración al laboratorio de microbiología de la Facultad de Medicina Veterinaria, Universidad Nacional Mayor de San Marcos, Lima. Las muestras fueron centrifugadas a $5000 \mathrm{~g}$ durante 10 minutos y los sueros se almacenaron en crioviales de $1.5 \mathrm{ml}$.

\section{Prueba de Inmunodifusión en Gel de Agar (IDGA)}

El diagnóstico de brucelosis canina se realizó mediante la prueba de IDGA (Véliz et al., 1974), la cual se basa en una reacción de precipitación antígeno-anticuerpo en una fase líquida, donde es posible visualizar bandas de precipitación. Se utilizó el antígeno de B. canis para evitar la reacción cruzada con otras especies de Brucella. La prueba se considera positiva si se evidencia un halo de precipitación a las 24-48 horas.

\section{Análisis de la Información}

La seroprevalencia fue corregida mediante la fórmula de Thrusfield (1990) a partir de la sensibilidad (91.7\%) y especificidad (100\%) de la prueba de IDGA. La seroprevalencia se expresó en porcentaje con intervalos de confianza (IC) al 95\%.

Se evaluó la asociación estadística entre las variables de la encuesta con los resultados de la prevalencia corregida. Se realizó el análisis de regresión logística multinomial (Hosmer y Lemeshow, 2002) para la evaluación del efecto de las variables incluidas en la encuesta sobre los resultados de seroprevalencia, con un nivel de significancia de 0.05. El análisis se hizo con el paquete estadístico STATA 12 (Stata Corp LP, EEUU).

\section{Resultados}

En el Cuadro 1 se puede observar que 14 de 288 canes resultaron seropositivos a $B$. canis, lo cual corresponde a una seroprevalencia de $4.9 \pm 1.8 \%$ y una seroprevalencia corregida de $5.3 \pm 2.6 \%$. No se encontró una asociación estadística entre las variables en estudio y la seropositividad a $B$. canis.

Solo una hembra tuvo historial de abortos y resultó negativa a B. canis. Asimismo, seis hembras tuvieron historia de crías nacidas muertas pero todas resultaron negativas a B. canis.

\section{Discusión}

La seroprevalencia encontrada en el presente estudio fue menor a la reportada en estudios previos en el país (Reyes, 1977; Ramírez et al., 2006). No obstante, se debe indicar que el estudio de Reyes (1997) se llevó a cabo en criaderos y albergues de perros, los cuales son considerados como grupos de mayor riesgo y, por lo tanto, proclives 
Cuadro 1. Seroprevalencia ${ }^{1}$ a brucelosis canina $(n=288)$ en el distrito de los Olivos, Lima (2012)

\begin{tabular}{|c|c|c|c|c|}
\hline \multirow[b]{2}{*}{ Variable } & \multicolumn{2}{|c|}{ Muestreados } & \multirow{2}{*}{$\begin{array}{l}\text { Seroprevalencia } \\
\quad \pm \mathrm{IC}^{2}\end{array}$} & \multirow{2}{*}{$\begin{array}{l}\text { Seroprevalencia } \\
\text { corregida } \pm \text { IC }\end{array}$} \\
\hline & $\begin{array}{l}\text { Total } \\
\text { (n) }\end{array}$ & $\begin{array}{l}\text { Positivos } \\
\text { (n) }\end{array}$ & & \\
\hline \multicolumn{5}{|l|}{ Sexo } \\
\hline Hembra & 131 & 7 & $5.3 \pm 3.9$ & $5.8 \pm 4.0$ \\
\hline Macho & 157 & 7 & $4.5 \pm 3.2$ & $4.9 \pm 3.4$ \\
\hline \multicolumn{5}{|l|}{ Edad } \\
\hline$<1$ año & 87 & 2 & $2.3 \pm 3.8$ & $2.5 \pm 3.3$ \\
\hline 1 a 4 años & 118 & 7 & $5.9 \pm 3.7$ & $6.5 \pm 4.4$ \\
\hline 5 a 8 años & 62 & 5 & $8.1 \pm 6.4$ & $8.8 \pm 7.1$ \\
\hline 9 a 15 años & 21 & 0 & - & - \\
\hline \multicolumn{5}{|l|}{ Condición fisiológica } \\
\hline No castrado(a) & 257 & 13 & $5.1 \pm 2.0$ & $5.5 \pm 2.8$ \\
\hline Castrad o(a) & 31 & 1 & $3.2 \pm 6.2$ & $3.5 \pm 6.5$ \\
\hline \multicolumn{5}{|l|}{ Sale a pasear } \\
\hline Sí & 246 & 12 & $4.9 \pm 2.7$ & $5.3 \pm 2.8$ \\
\hline No & 42 & 2 & $4.8 \pm 7.6$ & $5.2 \pm 6.7$ \\
\hline \multicolumn{5}{|l|}{ Ha sido cruzado } \\
\hline Sí & 67 & 1 & $1.5 \pm 4.1$ & $1.6 \pm 3.0$ \\
\hline No & 158 & 13 & $8.2 \pm 3.2$ & $9.0 \pm 4.5$ \\
\hline Total & 288 & 14 & $4.9 \pm 1.8$ & $5.3 \pm 2.6$ \\
\hline
\end{tabular}

a tener frecuencias más altas de seropositividad. Asimismo, la prueba de IDGA tiene un alto nivel de especificidad (100\%), mientras que en el otro estudio se utilizó la prueba de aglutinación con mercaptoetanol que tiene niveles de sensibilidad y especificidad más bajos, por lo que es probable que algunos animales hayan sido falsos positivos.

Los estudios epidemiológicos han demostrado que la brucelosis canina está asociada a poblaciones caninas específicas
(Castillo et al., 2002), como criaderos de perros y albergues, donde la historia de abortos es un predictor de la enfermedad. No obstante, la seroprevalencia hallada es considerada como baja, más aún, si se toma en cuenta que no se encontraron seroreactores a $B$. canis en la población de hembras en edad reproductiva ( $<1$ año). Estos resultados, sin embargo, pueden asociarse a la falta de representatividad de los datos y no a la ausencia de la enfermedad en este grupo de animales. 
La ausencia de predisposición por sexo para infección por B. canis es coincidente con los estudios de Carmichael y Joubert (1988), Castillo et al. (2002) y Hollet (2006), aunque es importante considerar que la infección en machos es una fuente relativamente más importante para la transmisión de la enfermedad, debido al arresto de la bacteria en la próstata que dificulta su tratamiento (Boeri et al., 2008).

Los perros pueden infectarse en cualquier etapa de su vida, aunque existe una mayor predisposición a la infección cuando alcanzan la edad reproductiva. No obstante, los resultados no demostraron diferencias significativas a seropositivad de $B$. canis entre los grupos etarios, resultado similar a los reportes de Megid et al. (1999) y Castillo et al. (2002).

La escasa diferencia en seropositividad entre canes castrados(as) y enteros pudo deberse a la escasa representatividad de los primeros en el estudio. Asimismo, es también probable que los canes pueden haberse infectado antes de la remoción de sus órganos reproductivos y que los anticuerpos hayan persistido en el tiempo. Por otro lado, la mayor proporción de canes seropositivos sin historial reproductivo que en aquellos con historial de haberse apareado, aunque sin deferencia estadística es contraria a los resultados obtenidos por Ramírez et al. (2006), quienes demostraron lo contrario. Existe la posibilidad de que algunos encuestados no hayan brindado información verdadera sobre el historial reproductivo de sus mascotas, y que algunos canes hayan tenido actividad reproductiva sin que sus dueños se hayan percatado.

\section{Conclusiones}

- La seroprevalencia de brucelosis canina en el distrito de Los Olivos, Lima, fue de $4.9 \pm 1.8 \%$ y la seroprevalencia corregida fue de $5.3 \pm 2.6 \%$.
- No se encontró una asociación significativa entre edad, sexo, condición fisiológica, hábitos de paseo e historial reproductivo con la seroprevalencia de brucelosis canina.

\section{Literatura Citada}

1. Acha P, Szyfres B. 2003. Zoonosis y enfermedades transmisibles comunes al hombre y a los animales. Vol 1. $3^{\mathrm{a}}$ ed. Washington DC, EEUU: Oficina Panamericana de la Salud. Publicación Científica y Técnica N ${ }^{\circ} 580.398$ p.

2. Ahlborn A, Norrel S. 1990. Introduction to model epidemiology. $2^{\text {nd }}$ ed. USA: Epidemiology Resources. 273 p.

3. Boeri E, Escobar GI, Ayala SM, SosaEstani S, Lucero NE. 2008. Canine brucellosis in dogs in the city of Buenos Aires. Medicina (B. Aires) 68: 291-297.

4. Carmichael LE, Joubert J. 1988. Transmission of Brucella canis by contact exposure. Cornell Vet 78: 63-73.

5. Carmichael LE, Kenney RM. 1968. Canine abortion caused by Brucella canis. J Am Vet Med Assoc 152: 605616.

6. Castillo V, Cotrino V, Moreno C. 2002. Encuesta serológica sobre Brucella canis en pacientes atendidos en la clínica de pequeños animales de la Facultad de Medicina Veterinaria y Zootecnia de la Universidad Nacional de Colombia. Arch Med Vet 13: 22-25.

7. Hollett RB. 2006. Canine brucellosis: outbreaks and compliance. Theriogenology 66: 575-587. doi: 10.1016/ j.theriogenology.2006.04.011

8. Hosmer DW, Lemeshow S. 2000. Applied logistic regression. $2^{\text {nd }}$ ed. Canada: John Wiley \& Sons. 375 p.

9. Megid J, Britto A, Moraes C, Nava N, Agottani J. 1999. Epidemiological assessment of canine brucellosis. Arq Bras Med Vet Zootec 51: 94-98. doi: 10.1590/S0102-09351999000500007 
10. Ramírez H, Calle S, Echevarría L, Morales S. 2006. Prevalencia de brucelosis canina en dos distritos de la Provincia Constitucional del Callao. Rev Inv Vet Perú 17: 39-43. doi: 10.15381/ rivep.v17i1.1456

11. Reyes F. 1977. Diagnóstico serológico de brucelosis canina causada por Brucella canis en Lima Metropolitana. Tesis de Médico Veterinario. Lima: Univ Nacional Mayor de San Marcos. 26 p.

12. Rhoades HE, Mesfin GM. 1980. Brucella canis infection in a kennel. Vet Med Small Anim Clin 75: 595-599.

13. Rousseau P. 1985. Brucella canis infection in a woman with fever of unknown origin. Postgrad Med 78: 249-257.

14. Schoenemann J, Lutticken $R$, Scheibner E. 1986. Brucell canis infection in man. Dtsch Med Wochenschr 111(1): 20-22.
15. Shin S, Carlmichael LE. 1999. Canine brucelosis caused by Brucella canis. In: Carmichael LE (ed). Recent advances in canine infectious diseases. Ithaca, NY: International Veterinary Information Service. [Internet]. Available in: ww w.ivis.org/a d vances / Infect_Dis_Carmichael/shin/ chapter_frm.asp?LA=1

16. Steele J, Stoenner H, Kaplan W, Torten M. 1979. Handbook series in zoonoses. Section A. USA: CRC Press. 643 p.

17. Thursfield M. 1990. Epidemiología veterinaria. España: Ed Acribia. 42 p.

18. Véliz N, Rosadio R. Barreto D, Castagnino D. 1974. Difusión en agar gel. Prueba de campo para el estudio de la epididimitis a Brucella ovis. Rev Inv Pec 23(1): 23-28. 